\title{
Lateral Stiffness of Steel Bridge I-Girders Braced by Metal Deck Forms
}

\author{
O. Ozgur Egilmez ${ }^{1}$; Reagan S. Herman²; and Todd A. Helwig ${ }^{3}$
}

\begin{abstract}
The lateral-torsional buckling capacity of steel bridge girders is often increased by incorporating bracing along the girder length. Permanent metal deck forms (PMDF) that are used to support the wet concrete deck during bridge construction are a likely source of stability bracing; however, their bracing performance is greatly limited by flexibility in the connections currently used with the formwork. This paper outlines results from a research study that assessed and improved the bracing potential of metal deck forms used in bridge applications. The research study included shear tests of PMDF panels, and also lateral displacement and buckling tests of twin girder systems braced with PMDF. This paper will provide key results from the shear panel tests and then focus on the lateral displacement tests. Parametric investigations of PMDF bracing behavior were conducted using finite-element analyses and the results from the lateral displacement tests served a critical role in calibrating the finite element models. This paper documents key results from lateral load tests of 17 girder-PMDF systems using a variety of bracing details and PMDF thickness values.
\end{abstract}

DOI: 10.1061/(ASCE)1084-0702(2009)14:1(17)

CE Database subject headings: Stiffness; Bridges, steel; Bracing; Bridge decks; Buckling.

\section{Introduction}

The limit state of lateral-torsional buckling plays an important role in the sizing of steel bridge girders. The critical stage for lateral-torsional buckling usually occurs during placement of the concrete deck, when the steel section must carry the entire construction load. The buckling capacity of the girders can be increased by reducing their laterally unsupported length using bracing positioned either at discrete locations or continuously along the girder span. However, the cross frames or diaphragms conventionally used to brace steel bridge girders are relatively expensive to fabricate, complicate girder erection, and can also lead to fatigue-sensitive details; therefore, alternate sources of bracing are of interest. A potential source of bracing is the permanent metal deck forms (PMDF) that are commonly utilized to support the wet concrete bridge deck during construction. Although the acronym "PMDF" will be used throughout this paper, some engineers may be more familiar with other equivalent terms including stay-in-place forms or permanent metal deck. Although metal deck forms are frequently relied upon for lateral bracing in the building industry, the forms are not generally considered for bracing in bridge applications because of the flexibility in the connection detail used with the formwork in bridges. The differences between the deck form connections used in buildings and

\footnotetext{
${ }^{1}$ Assistant Professor, Dept. of Civil Engineering, Izmir Inst. of Technology, Izmir, Turkey 35430.

${ }^{2}$ Assistant Research Professor, Dept. of Civil Engineering, Johns Hopkins Univ., Baltimore, MD 21218. E-mail: rherman@uh.edu

${ }^{3}$ Assistant Professor, Dept. of Civil Architectural and Environmental Engineering, Univ. of Texas at Austin, Austin, TX 78712.

Note. Discussion open until June 1, 2009. Separate discussions must be submitted for individual papers. The manuscript for this paper was submitted for review and possible publication on March 5, 2007; approved on July 31, 2007. This paper is part of the Journal of Bridge Engineering, Vol. 14, No. 1, January 1, 2009. CASCE, ISSN 1084-0702/ 2009/1-17-25/\$25.00.
}

those used in bridges are discussed in the background section.

The purpose of this study outlined in this paper was to enhance the understanding of PMDF bracing behavior, simultaneously improving deck connection details for steel bridge applications. The research included both laboratory investigations and finiteelement analysis (FEA) studies. The laboratory studies included several test phases to isolate component behavior from system behavior. The first phase of the laboratory investigations consisted of shear tests to assess the stiffness of the PMDF, and although the shear panel tests provided valuable information on the shear stiffness and connection behavior of the PMDF alone, the stiffness of girder systems braced with the forms also had to be assessed. Lateral displacement tests of a twin girder system braced with PMDF were conducted to measure the stiffness of the girder-PMDF system. The results from the stiffness tests of girders braced with PMDF were then used as a basis for calibrating finite-element models. The role of the lateral displacement testing program was critical for finite-element calibration as there are a number of characteristics of PMDF bracing systems that were difficult to capture with the shear panel tests. After the finiteelement model was calibrated, it was then used to conduct parametric investigations of the deck forms' performance as a brace.

\section{Background}

Corrugated metal sheeting is routinely utilized as bracing in building applications. Due to its large in-plane shear resistance, the sheeting is typically treated as a shear diaphragm that can provide lateral load resistance and serve as stability bracing. Metal sheeting is also a potential source of bracing in steel bridges; however, the shape and connection of the corrugated sheeting used as deck formwork in bridges differs substantially from that used in buildings. In terms of their relative shapes, the deck forms used in buildings are typically open at the ends, whereas the ends of the bridge forms are closed. But the most important difference between the building and bridge forming 


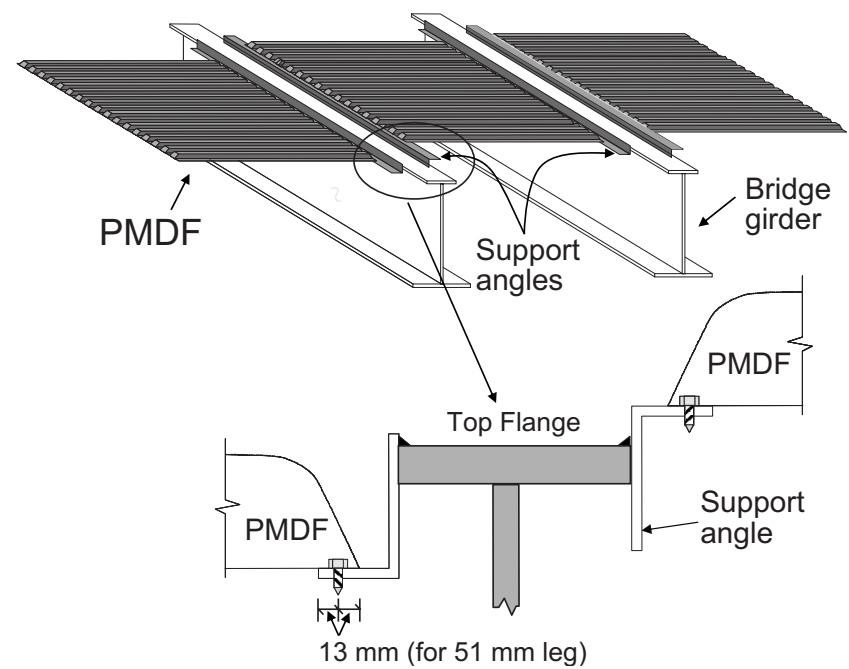

Fig. 1. Eccentric connection currently utilized in the bridge industry

systems in terms of bracing performance is the connection details between the girders and the metal deck. In buildings, the deck forms are generally continuous across the beams and are fastened directly to the top flanges using puddle welds, shear studs, or mechanical fasteners. However, forms used in bridges generally span between adjacent girders and are attached to the girder with an eccentric connection using a support angle as shown in Fig. 1. The eccentricity of the connection is defined as the distance from the bottom of the top flange to the bottom of the support angle.

The support angle detail used in bridges allows the contractor to adjust the form elevation to account for changes in flange thickness along the girder length and differential camber between adjacent girders. The support angle can be oriented either up or down depending on the haunch detail and necessary elevation adjustment. The support angle connection allows the contractor to achieve a uniform deck thickness along the length of the bridge; however, results by Helwig et al. (2005) showed that the eccentricity in the connection substantially reduces the stiffness of the deck form system as a bracing element.

\section{Shear Panel Tests}

The first phase of this research study consisted of shear panel experiments using a test frame, such as the one shown in Fig. 2.

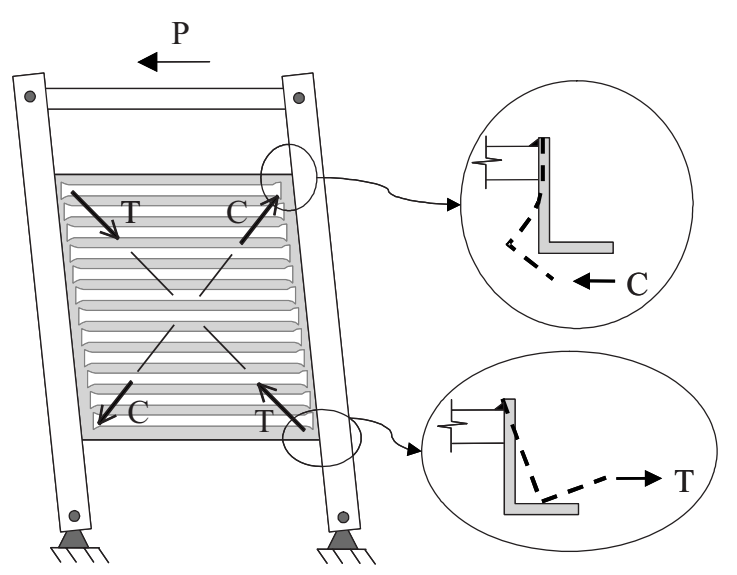

Fig. 2. Shear test frame with PMDF specimen

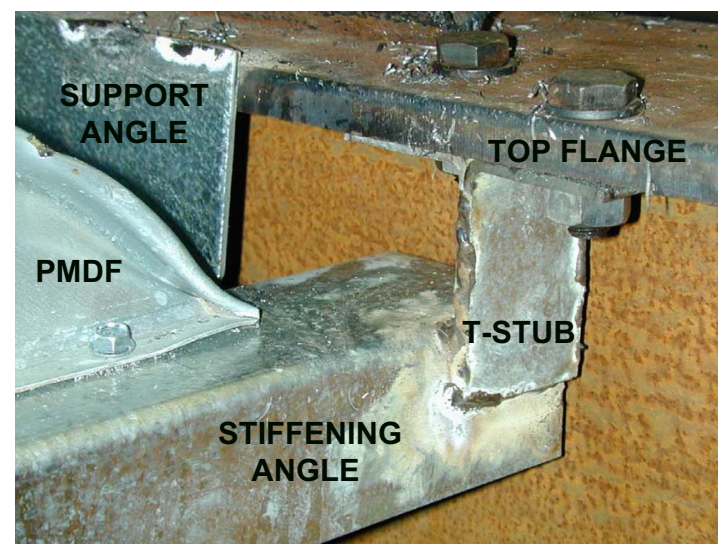

Fig. 3. Stiffening angle connection

In the shear tests, the PMDF system was subjected to constant in-plane shear along its length. Depending on the location along the panel, the support angle either pulled away from or bent under the girder flange as shown in Fig. 2. This angle deformation pattern was observed in all the laboratory tests of PMDF with eccentric support angle connections.

The shear tests of PMDF attached with conventional connection details showed that the support angle flexibility limits the PMDF system stiffness. One of the goals of the research program was to develop simple modifications to the connection details to control the support angle deformations so that the bracing performance of the PMDF system could be improved. Although considering possible modifications to the connection details, an important consideration was that the modified details continue to permit adjustment of the PMDF elevation. A variety of connection details were considered in the shear tests of PMDF panels, and finally a detail that adds transverse "stiffening angles" to the PMDF system was selected. These stiffening angles span between the top flanges of adjacent girders and are located at intermittent locations along the girder length. Each stiffening angle is positioned at a sidelap location between adjacent PMDF sheets so that the forms can be screwed directly to the angle. The stiffening angle spacings that were used in the shear panel tests ranged from 2.44 to $4.88 \mathrm{~m}$ (from 8.0 to $16.0 \mathrm{ft}$ ), with girder spacings from 2.44 to $2.74 \mathrm{~m}$ (from 8.0 to $9.0 \mathrm{ft}$ ). Fig. 3 shows the connection detail that was used between the girder flange and the stiffening angle. The connection consisted of a T-shaped section that was fabricated from pieces of the support angle and then bolted to the flange using $16 \mathrm{~mm}$ (0.625 in.) diameter bolts. The bolts were offset by $2.54 \mathrm{~cm}$ ( 1 in.) to provide moment resistance. The bolted connections were used so that the stiffening angles could be easily added or removed during the testing program. In practice, this connection can be made with hot rolled $\mathrm{T}$ sections or connection plates that can be shop welded to the girders during fabrication. Results from shear panel tests with the modified connection detail were presented and discussed by Helwig et al. (2005). The modified connection essentially eliminates the deformations in the support angles and results in substantial increases in the shear stiffness of the PMDF system.

\section{Objectives of Lateral Displacement Tests}

The shear panel tests provided a means to monitor the performance of various connection details and obtain a measure of the shear properties of the PMDF systems; however, tests to measure 
the stiffness characteristics of girders braced by PMDF were needed to improve the understanding of the system from a lateral bracing perspective. The stiffness of the system was assessed by applying lateral loads on twin girders braced using PMDF. The response of the system was measured as it was subjected to deformations consistent with the profiles experienced during lateraltorsional buckling. Twin girder systems were used as they provide a conservative estimate of capacity compared to multigirder systems. In multigirder systems the number of PMDF panels available to brace each girder is increased.

Another issue that was evaluated with the twin girder system tests was the impact of the girder flange thickness in cases where the support angle is bent under the flange as was shown in Fig. 2. The stiffness of the support angle is affected by the flange thickness when the angle is bent under the flange. Because the flange thickness of the shear panel testing frame differed from that expected for bridge girders, a measure of the stiffness of the support angle in an actual bracing application with flange thickness values consistent with typical bridge girders needed to be obtained.

One issue that complicates the response of PMDF in bracing applications is the fact that the shear strains the PMDF is subjected to vary along the girder length unlike in the shear panel tests, where the PMDF was subjected to constant shear strains. In the lateral load tests used to measure the stiffness of girders braced with PMDF, the shear strain distributions were consistent with the deformations expected during girder buckling. Thus the lateral displacement tests provided more meaningful data for use in sizing the shear diaphragms used in the FEA models. The following section outlines the results from the lateral displacement tests.

\section{Lateral Displacement Test Setup}

The experiments detailed in this paper were conducted in the structural engineering laboratory at the University of Houston. The twin girder system that was used in the lateral load and buckling tests had a span of $15 \mathrm{~m}(50 \mathrm{ft})$, and the supports used provided adequate flexibility to simulate simply supported boundary conditions in the longitudinal direction of the test girders. No intermediate cross frames were used along the length of the girders.

Twist of the girders at the supports was restrained using angle brackets, similarly to the restraint that would be provided by support cross frames in a real bridge. The angle bracket details allowed for adjustment of the girder's plumbness at the supports, and the brackets were configured to provide minimal warping restraint as discussed by Helwig et al. (2005). Another measure undertaken to reduce warping restraint at the supports was use of thrust bearings to lessen the contact friction between the girders and the supporting sections. The efforts to minimize warping restraint at the support locations were undertaken to approach the idealized boundary conditions utilized in the finite-element model.

Three different types of ASTM A992 Grade 345 (US: Grade 50) beams were included in the testing program. The first test used a modified $\mathrm{W} 760 \times 134(\mathrm{US}$ : W30 $\times 90)$ beam section. The top flange of the $\mathrm{W} 760 \times 134$ was flame cut from the original $264.2 \mathrm{~mm}$ (10.4 in.) width to $158.8 \mathrm{~mm}$ (6.25 in.). This produced a singly symmetric section with $\rho=I_{y c} / I_{y}=0.18$, where $I_{y c}$ and $I_{y}=$ respective moment of inertias of the compression flange and the entire cross section about a vertical axis through the web. The $\rho$ value of 0.18 used for the modified W760 $\times 134$ section is near
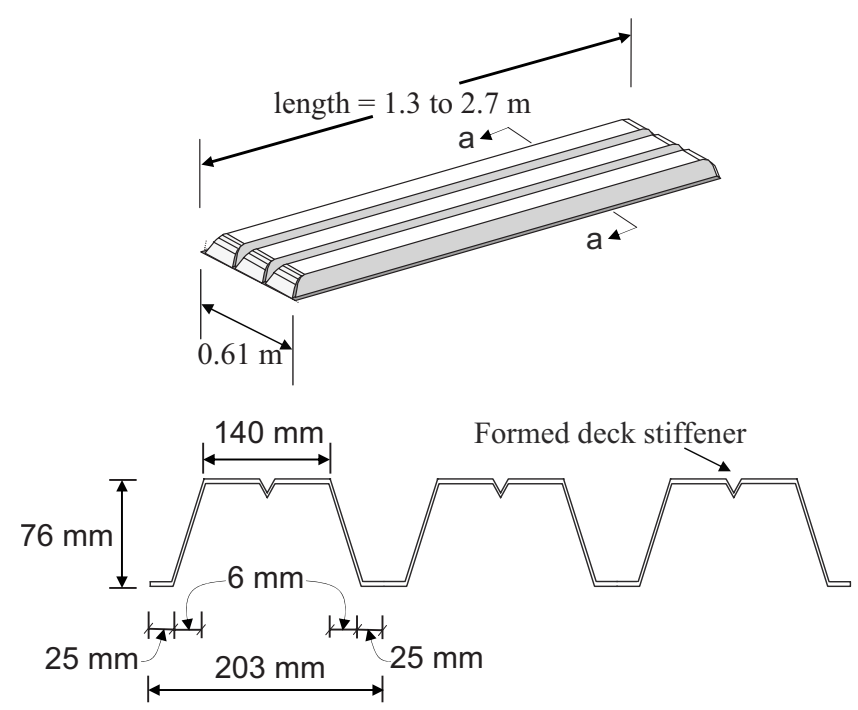

Section a -a

Fig. 4. PMDF profile

the lower bound of $\rho=0.1$ that is permitted in the American Association of State Highway and Transportation Officials (AASHTO) Standard Specifications (2002). The span to depth ratio for the modified $\mathrm{W} 760 \times 134$ was 20 and the top flange width to depth ratio was 0.21 . The modified $\mathrm{W} 760 \times 134$ girders were spaced at $2.93 \mathrm{~m}(9.58 \mathrm{ft})$ center-to-center and the deck forms had a span of $2.72 \mathrm{~m}(8.92 \mathrm{ft})$.

The other two girders that were tested were doubly symmetric W460× 177 (US: W18×119) and W460×106 (US: W18×71) rolled sections. The $\mathrm{W} 460 \times 177$ section was chosen to match girders that are being used in two bridges in Houston that will use PMDF as construction bracing and implement the findings of this research program. The span to depth ratio for the $\mathrm{W} 460 \times 177$ section was 32 , and its flange width to depth ratio was 0.59 . The spacing of the girders in the implementation bridges varies from 1.62 to $1.83 \mathrm{~m}$ (from 5.83 to $6.00 \mathrm{ft}$ ). The center-to-center spacing used in the laboratory tests was set to the minimum $1.62 \mathrm{~m}$ $(5.31 \mathrm{ft})$ spacing, which resulted in use of deck forms that had a span of $1.27 \mathrm{~m}(4.17 \mathrm{ft})$. A W460 $\times 106$ beam was chosen as the third test girder as it had the same depth but much narrower flanges than the W460 $\times 177$ section. The narrow flanges of the W460 $\times 106$ make it more susceptible to buckling at lower load levels, thereby placing a larger demand on the PMDF bracing. The W460 $\times 106$ beam had the same span to depth ratio of 32 as the $\mathrm{W} 460 \times 177$ section, but the flange width to depth ratio of 0.41 for the $\mathrm{W} 460 \times 106$ was significantly less than that of the $\mathrm{W} 460 \times 177$ section. The $\mathrm{W} 460 \times 106$ girders were spaced at $1.52 \mathrm{~m}(5.00 \mathrm{ft})$ center-to-center to accommodate placement of deck forms with a $1.27 \mathrm{~m}(4.17 \mathrm{ft})$ span so that the same forms could be used in the tests of both the W460 $\times 177$ and W460 $\times 106$ girders.

The PMDF tested in this study were $76 \times 203[76 \mathrm{~mm}(3 \mathrm{in}$.) depth, $203 \mathrm{~mm}$ (8 in.) pitch] bridge deck forms with factory closed ends. Fig. 4 shows the cross-section profile of the PMDF. The width of the forms was $610 \mathrm{~mm}$ ( $24 \mathrm{in}$.), and the forms that were tested had sheet thicknesses of $0.91,1.22$, and $1.63 \mathrm{~mm}(20$, 18, and $16 \mathrm{ga})$. The PMDF was made from ASTM A653 material with a minimum nominal yield strength of $345 \mathrm{MPa}(50 \mathrm{ksi})$ and an ultimate strength of $483 \mathrm{MPa}(70 \mathrm{ksi})$.

The PMDF sheets were supported on cold-formed L76 $\times 51$ 
Stiffening angles

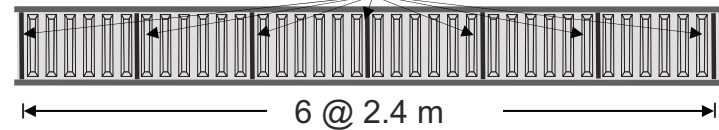

Stiffening angles

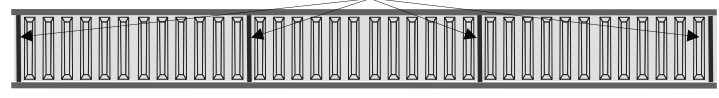

$3 @ 4.9$ m

Stiffening angles

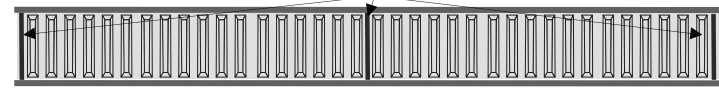

$2 @ 7.3 \mathrm{~m}$

Fig. 5. Stiffening angle configurations

$\times 3.3 \mathrm{~mm}$ or $\mathrm{L} 76 \times 76 \times 3.3 \mathrm{~mm}(\mathrm{~L} 3 \times 2$ or L3 $\times 310 \mathrm{ga})$ galvanized angles. The $\mathrm{L} 76 \times 51 \times 3.3 \mathrm{~mm}$ angles are typical of those employed in bridge construction; however, L76 $\times 76 \times 3.3 \mathrm{~mm}$ angles were also used to increase fastener edge distance, which, as will be discussed later in this paper, increased the stiffness and strength of the connections. The stiffening angles (shown in Fig. 3) were made from material satisfying ASTM A653 with minimum nominal yield and ultimate strengths of 255 and $359 \mathrm{MPa}$ (36 and $50 \mathrm{ksi}$ ), respectively. The PMDF was fastened using selfdrilling \#14 TEKS screws that were $19 \mathrm{~mm}$ (0.75 in.) long with a $6 \mathrm{~mm}$ (0.25 in.) diameter. These screws were used for both the end and sidelap connections. At sidelaps, the screws were fastened at a maximum center-to-center spacing of $460 \mathrm{~mm}$ (18 in.) as required by the Texas Department of Transportation (TxDOT) PMDF Standards (2004). The forms were fastened to the support angles in every trough of the sheeting. The $76 \mathrm{~mm}$ (3 in.) long leg of the support angles was welded to the top flanges with $3 \mathrm{~mm}$ $(1 / 8$ in.) intermittent fillet welds. The fillet welds were $50 \mathrm{~mm}$ ( 2 in.) long and spaced at $305 \mathrm{~mm}$ (12 in.) intervals. The welds at the ends of the support angles were $75 \mathrm{~mm}$ (3 in.) long.

The support angles were always welded to the top flanges with the maximum eccentricity expected in practice $[\sim 70 \mathrm{~mm}$ (2.75 in.)]. The actual eccentricity in bridges will often be significantly less than this maximum value at many locations along the girder length; therefore the details tested in the laboratory are conservative and expected to represent a worst-case scenario. Stiffening angles were provided near the ends of the girders and at intermediate locations along the girder span. Three different stiffening angle spacings of $2.4,4.9$, and $7.3 \mathrm{~m}(8,16$, and $24 \mathrm{ft})$ were tested as illustrated in Fig. 5. Tests were also conducted using conventional PMDF details without stiffening angles.

A total of 17 PMDF systems were tested with three different girder cross sections. The girders were kept in the elastic range in the lateral load tests so that they could be reused in subsequent tests. Of the 17 total tests, 13 were conducted on the singly symmetric modified $\mathrm{W} 760 \times 134(\mathrm{US}$ : W30 $\times 90)$, one was conducted on the W460 $\times 177$ (US: W18 $\times 119)$, and three were conducted on the W460 $\times 106$ (US: W $18 \times 71$ ). The thickness of the PMDF systems tested with the modified W760 $\times 134$ included 5 tests with $0.91 \mathrm{~mm}$ (20 ga) PMDF, 3 tests with $1.22 \mathrm{~mm}$ (18 ga) PMDF, and 5 tests with $1.63 \mathrm{~mm}$ (16 ga) thick deck systems. A PMDF thickness of $0.91 \mathrm{~mm}$ (20 ga) was used in all tests of the $\mathrm{W} 460 \times 177$ and $\mathrm{W} 460 \times 106$ beams. It is not possible to discuss

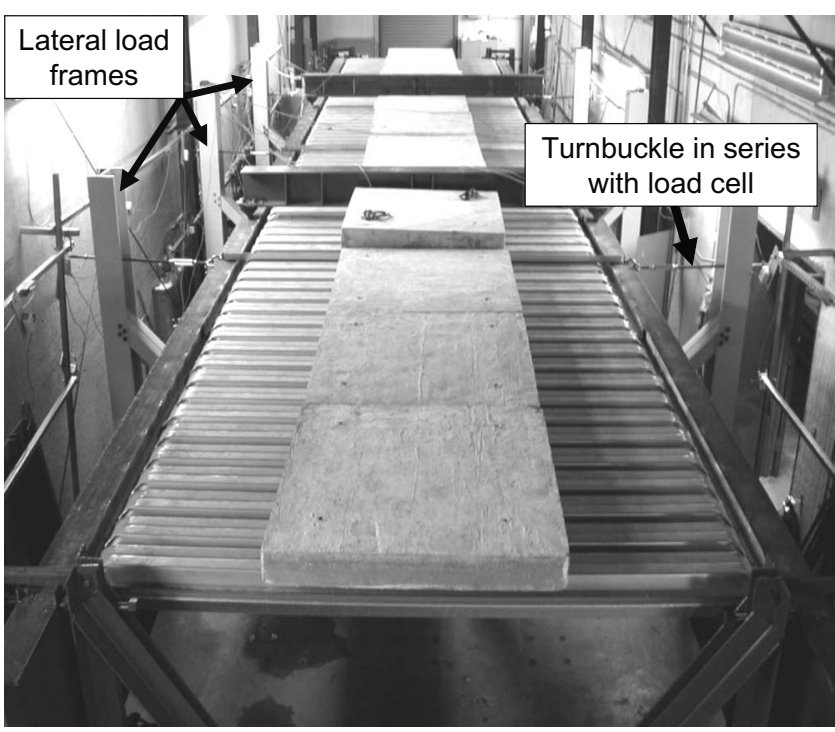

Fig. 6. Twin girder test setup

all results from the lateral displacement testing program within the length requirements of this paper; therefore, the discussion of results will focus only on the modified singly symmetric W760 $\times 134$ section. The general trend of results for this beam is analogous to those observed for the other two beam sections. More information on the tests of the W460 × 177 and W460 $\times 106$ beams can be obtained from Helwig et al. (2005) and Egilmez (2005).

For the initial tests of $1.22 \mathrm{~mm}(18 \mathrm{ga})$ thick deck on the modified $\mathrm{W} 760 \times 134$ beams, the PMDF panels were tested with and without superimposed dead load. Superimposed dead load was applied using $1,220 \times 1,220 \times 150 \mathrm{~mm}(4 \times 4 \times 0.5 \mathrm{ft})$ concrete panels that weighed approximately $450 \mathrm{~kg}(1000 \mathrm{lbs})$ each. Twelve of the panels were distributed along the length of the PMDF as shown in Fig. 6. With the addition of the superimposed dead weight, the lateral stiffness of the PMDF systems increased by approximately $8-10 \%$ due to increased friction between contact surfaces. In most bracing and buckling applications for girders, a significant portion of the loading comes from the weight of wet concrete on the PMDF system. Therefore, the friction accompanying application of dead loads on the deck is present when the PMDF is called on to provide bracing; so, after the initial series of tests, all subsequent experiments were conducted with concrete panels on the deck. The results discussed in this paper will provide engineers with an indication of the range of deck stiffness values that were measured in the laboratory tests. The results also provide other researchers the data required to simulate realistic values of shear diaphragm stiffness for computational models of girder-PMDF systems during construction.

\section{Testing Procedure}

The stiffness of the twin girder system with PMDF bracing was measured by applying lateral loads at the quarter-points and/or midspan of the girder length. The loads were applied using lateral load frames positioned at three locations along the girder length as shown in Fig. 6. In the tests, turnbuckles were used to connect the top flange of the girders to the lateral load frames located on both sides of the girder system. Turnbuckles were positioned at each of the lateral load testing frames shown in Fig. 6, and $L 76$ 


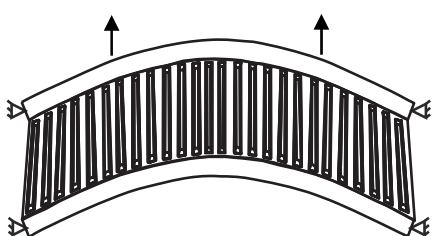

Case A: Quarter-point displacement
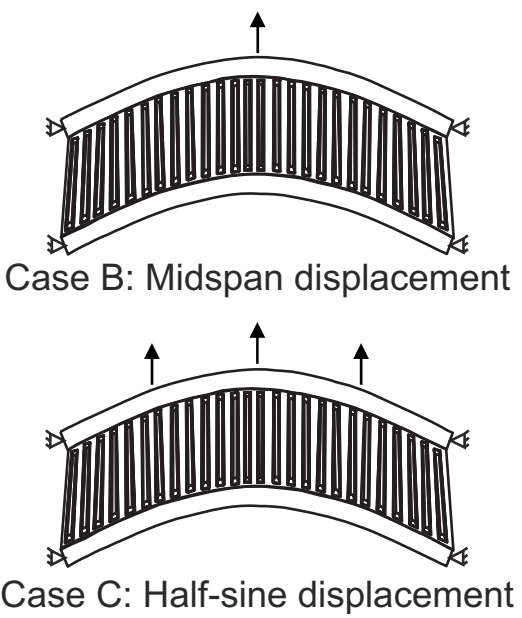

Fig. 7. Lateral displacement profiles

$\times 51 \times 3.3 \mathrm{~mm}(L 3 \times 2) 10$ gauge $)$ angles were used to link the top flanges of the girders together at these locations so that the girders displaced in the same direction when pulled by the turnbuckles. Lateral displacements were applied to the girders by adjusting the turnbuckles and the forces in the turnbuckles were monitored using load cells. Linear potentiometers were used to measure the lateral deformation of the girders at the turnbuckle locations.

As noted earlier, the purpose of these tests was to measure the stiffness of twin girder systems braced with PMDF and use these stiffness measurements for calibrating FEA models. The models were then used in parametric buckling analyses later in the research study. To obtain a good measure of the system stiffness, three different deformation profiles were utilized as shown in Fig. 7. In Cases A and B, the girders were displaced by pulling only at the quarter-points or only at midspan. In Case $\mathrm{C}$, the girders were pulled at both the quarter-point and midspan locations to match the deformation of a half-sine curve ( $\Delta$ at midspan, and $0.707 \Delta$ at the quarter-points). In Case $\mathrm{C}$, a trial and error procedure was used to generate sine curve deformations as pulling at the quarterpoints causes a midspan displacement and vice versa. A measure of the lateral stiffness for the system was obtained by dividing the force in each turnbuckle by the corresponding lateral deflection at that turnbuckle. These experimental lateral stiffness values were then used to size the shear diaphragm models of the PMDF in the finite-element studies. The finite-element models were used in later work to predict the buckling capacity of the girder system.

An important component of the lateral testing program was obtaining stiffness values for PMDF braced girders that had deformation profiles like that experienced during lateral-torsional buckling of a girder system with no intermediate cross frames, namely lateral displacement of the compression flange along the girder length with maximum displacement at midspan and no displacement at the supports. The bracing contributions from a shear diaphragm are most substantial in regions along the beam length where the shear deformations are largest. Referring back to

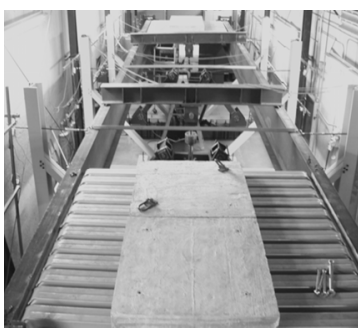

(a) Actual system

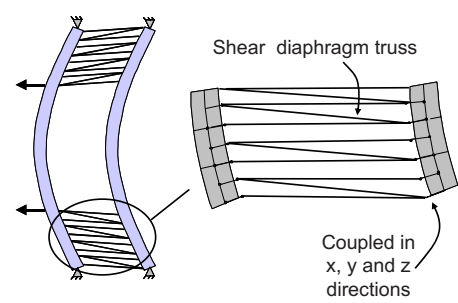

(b) Finite element model of system
Fig. 8. Partially decked tests

Fig. 7, the regions around the ends of the beam generated the largest shear deformation in the PMDF panels, whereas the PMDF near midspan had very little in-plane shear deformation. Although the PMDF is modeled as a shear diaphragm, the deformation pattern shown in Fig. 7 also engages the in-plane flexural stiffness of the PMDF sheets. From a bracing perspective, the in-plane flexural stiffness of the sheeting provides the most contribution out near midspan, where the top flange of the beam experiences the largest lateral deformation.

Although the sheeting does possess some in-plane flexural stiffness, the contribution of this stiffness was found to be relatively small during later buckling tests. Therefore, the primary stiffness quantity that is of interest in the lateral load tests is the in-plane shear stiffness of the PMDF bracing. The best way to capture this shear stiffness component was by using the Case A quarter-point loading defined in Fig. 7. As shown in Fig 8(a), tests were conducted with the Case A loading on partially decked (PD) systems where shear panels were installed near the ends of the girders. In later tests, fully decked (FD) girders were used since, as will be discussed, reasonable estimates of the effective shear stiffness could be obtained with the Case A loading on the FD system. Although different PD configurations were used, most tests were conducted with PMDF panels in the $3.65 \mathrm{~m}(12 \mathrm{ft})$ region adjacent to the support. This positioning was chosen to obtain the truest measurement of the shear stiffness of the PMDF system. All systems tested with PD configurations were also tested with full decks.

\section{Finite-Element Model}

The three-dimensional finite-element program ANSYS (2004) was used to model the laboratory test setup and to perform parametric studies of girders braced by PMDF. All analyses made use of linear elastic materials as the girder and deck systems remained elastic during the lateral displacement laboratory tests. A combination of shell, beam, and truss elements were used to model the structural components of the twin-girder system. The cross sections of the girders were modeled using eight-noded quadrilateral shell elements for the girder flanges and web. Two shell elements were used for each flange and four elements were used through the depth of the web. The aspect ratio of the shell elements were maintained as close to unity as possible.

The fillets of the rolled sections were modeled using twonoded beam elements that were rigidly coupled to the nodes at the flange to web junction. The fillets primarily affect the torsional stiffness of the rolled sections. The area that was provided for the fillet beam elements was found by subtracting the area of the rectangular flange and web elements from the gross cross sectional for the section. 
Finite-element models were built corresponding to each girder section and spacing tested in the laboratory. The girders were simply supported and twist was prevented at the supports by restraining the lateral movement at the top and bottom of the girder webs. The magnitudes and point of application of the loads that were imposed on the FEA model matched those that were applied in the laboratory.

A shear diaphragm truss panel model similar to that developed by Helwig and Yura (2006) was utilized to model the PMDF in the study. Fig. 8(b) shows an illustration of the truss panel model. The model was built up from two-node truss elements connected to the edges of the girder top flanges. Values of the effective shear modulus for the PMDF systems were determined from the laboratory quarter-span displacement (Case A in Fig. 7) test results. The laboratory tests were then used to calibrate the FEA model. The term "calibration" of the FEA model in this paper is used to describe the fact that the laboratory results were used to select appropriate areas for the shear diaphragm truss panels that were used to model the stiffness of the corrugated metal deck form systems. The area of the shear diaphragm truss panels was adjusted until the FEA model acquired the same lateral stiffness as that indicated in the laboratory tests. Thus, a model for the PMDF system that captured the true system stiffness of the form system was produced. Then the shear diaphragm truss panel system sized from the lateral displacement tests results was used in a FEA model of a shear test frame similar to that shown in Fig. 2 to obtain a measure of the effective shear modulus, $G^{\prime}$, for each of the PMDF systems with various PMDF bracing details. The $G^{\prime}$ values are reported in the stiffness tables discussed in the following section for the bridge deck gauges that were tested in this study, which are typical of those used in steel bridges. These $G^{\prime}$ reference values for PMDF systems, with either conventional connection details or the stiffened details recommended in this paper, can now be used in future work to model the true stiffness of complex corrugated PMDF systems using simple shear diaphragm truss models.

\section{Lateral Stiffness Values for Partially and Fully Decked Systems}

Although three different girder cross-sections were tested in the laboratory, the discussion of results will focus on the W760 $\times 134$ with the reduced top flange, which were similar to the results for the other sections as previously noted. Complete results for all sections can be found in Egilmez (2005). Four tables containing select results for the modified W760 $\times 134$ section will be presented in the following discussion. The primary data presented in the tables are the lateral stiffness values for twin girder systems with 0.91 or $1.22 \mathrm{~m}$ thick deck and $\mathrm{L} 76 \times 51 \times 3.3$ or L76 $\times 76 \times 3.3 \mathrm{~mm}$ support and stiffening angles.

\section{Twin-Girder System Alone with No Decking}

Table 1 presents laboratory and FEA results for the twin girder system with modified W760 $\times 134$ sections alone without any decking. The first column identifies whether the results in a given row are from laboratory tests or FEA studies, and the second column identifies the PMDF type. The third and fourth columns list the effective shear stiffness $\left(G^{\prime}\right)$ of the PMDF and the results for a PD system with Case A quarter-point loading as shown in Fig. 8. There are obviously no entries in the $G^{\prime}$ and PD-Case A columns of Table 1 as there was no decking in these tests, but these columns are populated in later tables, which contain results for decked girder systems. The fifth and sixth columns contain the lateral stiffness values of the system when subjected to the Case A quarter-point loading and the Case B midspan loading, respectively. The lateral stiffness at the quarter-points is reported for the Case A loading, and the lateral stiffness at midspan is reported for Case B.

The last three columns of Table 1 present lateral stiffness values for the Case $\mathrm{C}$ loading. As shown in Fig. 7, loading was applied at both the quarter-points and midspan in Case $\mathrm{C}$ to generate a half-sine displacement profile. For Case C, lateral stiffness values at the quarter-spans are presented, followed by the stiffness at midspan, and finally the total lateral stiffness is presented in the last column of the table. Comparison of the lateral stiffness values in Table 1 for Cases A, B, and C loadings of the modified W760 $\times 134$ twin girder system with no deck shows that the FEA solutions were within approximately $1 \%$ of the measured results for all three lateral displacement profiles.

\section{Decked Twin-Girder System with L76 $551 \times 3.3 \mathrm{~mm}$ Support and Stiffening Angles}

Tables 2 and 3 present lateral stiffness values for the modified W760 $\times 134$ section with L $76 \times 51 \times 3.3 \mathrm{~mm}$ support and stiffening angles and $0.91 \mathrm{~mm}$ thick forms. The data in the tables include results for the conventional "unstiffened" PMDF system currently used in practice, and for systems using the modified connection details with stiffening angles spaced along the girder length as shown in Fig. 5. The asterisk in the table denotes the particular laboratory test that was used to calibrate the FEA model.

The columns used in Tables 2 and 3 are analogous to those in Table 1, except that the last five columns of Tables 2 and 3 are labeled FD-Case A, FD-Case B, and FD-Case C to indicate that FD systems were used in these tests. During the testing program it was found that reasonable measurements of the PMDF shear stiffness could be obtained from the Case A loading on the FD system; therefore PD configurations were not evaluated in later tests. Tests with all three loading configurations (Cases A, B, and C) were conducted on each FD system.

Comparing the stiffness values in Tables 2 and 3 for the 
Table 2. Modified W760×134 with L76 $\times 51 \times 3.3$ Angles and $0.91 \mathrm{~mm}$ Thick PMDF

\begin{tabular}{|c|c|c|c|c|c|c|c|c|}
\hline \multirow[b]{2}{*}{ Basis } & \multirow[b]{2}{*}{ PMDF type } & \multirow[b]{2}{*}{$\begin{array}{c}\mathrm{G}^{\prime} \\
(\mathrm{kN} / \mathrm{m}-\mathrm{rad})\end{array}$} & \multirow[b]{2}{*}{$\begin{array}{c}\text { PD-Case A } \\
(\mathrm{kN} / \mathrm{m})\end{array}$} & \multirow[b]{2}{*}{$\begin{array}{c}\text { FD-Case A } \\
(\mathrm{kN} / \mathrm{m})\end{array}$} & \multirow{2}{*}{$\begin{array}{c}\text { FD- } \\
\text { Case B } \\
(\mathrm{kN} / \mathrm{m})\end{array}$} & \multicolumn{3}{|c|}{ FD-Case C } \\
\hline & & & & & & $\begin{array}{c}\text { Midspan } \\
(\mathrm{kN} / \mathrm{m})\end{array}$ & $\begin{array}{c}\text { Qtr-point } \\
(\mathrm{kN} / \mathrm{m})\end{array}$ & $\begin{array}{c}\text { Total } \\
(\mathrm{kN} / \mathrm{m})\end{array}$ \\
\hline \multirow[t]{4}{*}{ Lab } & Unstiffened & - & $2,452^{\mathrm{a}}$ & 2,374 & 1,423 & 1,032 & 912 & 1,944 \\
\hline & Stiffened@2.4 m & - & $3,784^{\mathrm{a}}$ & 3,676 & 1,991 & 1,411 & 1,380 & 2,791 \\
\hline & Stiffened @4.9m & - & $3,608^{\mathrm{a}}$ & 3,482 & 1,751 & 1,080 & 1,931 & 3,011 \\
\hline & Stiffened @7.3 m & - & - & $3,468^{\mathrm{a}}$ & 1,939 & 1,247 & 1,711 & 2,958 \\
\hline \multirow[t]{4}{*}{ FEA } & Unstiffened & 1,787 & 2,452 & 2,452 & 1,278 & 735 & 1,330 & 2,065 \\
\hline & Stiffened@2.4 m & 2,698 & 3,784 & 3,818 & 1,979 & 1,156 & 2,032 & 3,188 \\
\hline & Stiffened@4.9m & 2,505 & 3,608 & 3,608 & 1,874 & 1,104 & 1,926 & 3,030 \\
\hline & Stiffened@7.3m & 2,750 & - & 3,468 & 1,804 & 1,051 & 1,892 & 2,943 \\
\hline
\end{tabular}

${ }^{\mathrm{a}}$ Denotes laboratory test used to calibrate FEA model.

decked systems to those in Table 1 for the girders alone show that for each loading case the total stiffness of the decked system was about 10-30 times that of the corresponding stiffness for the girder system with no deck. For systems with decks, interesting relationships can be observed within the data presented in a given table and by comparing corresponding results in the different tables. One trend that occurred throughout the testing program can be observed in the laboratory measurements of the unstiffened $0.91 \mathrm{~mm}$ system in Table 2. In the PD test with the Case A loading, the measured lateral stiffness was $2452 \mathrm{kN} / \mathrm{m}$ for the unstiffened deck. For the same loading case on the FD unstiffened system, the lateral stiffness dropped to $2,374 \mathrm{kN} / \mathrm{m}$. Although the difference in these two measured stiffness values is small, the trend goes against intuition as the stiffness for the FD system is less than that of the PD system. This seems to indicate that the stiffness goes down when more panels are added to the system, however, this trend was not observed in the FEA results. In the FEA solutions, the truss panels in the finite-element model were sized or calibrated using the results for the PD system with the Case A loading, so the FEA model of the unstiffened PD system obviously yielded a stiffness identical to the laboratory test value of $2,452 \mathrm{kN} / \mathrm{m}$. When the truss panels sized using the PD results were then used to predict the stiffness of the FD system, the results showed the exact same stiffness of $2,452 \mathrm{kN} / \mathrm{m}$. Thus, unlike the lab test results, the stiffness for the shear diaphragm FEA model does not go down when more panels are added, but instead remained constant.

It was determined that the slight reduction in stiffness values for the FD laboratory tests compared to the PD tests was actually due to the concrete panels shown in Fig. 6, which were placed on the decks to simulate the weight of the wet concrete on the forms. In the FD system, the concrete panels in the middle half of the span produce a $P$-delta effect that slightly reduces the measured stiffness of the system. In tests that were conducted without the superimposed concrete panels, the stiffness of the FD system was not reduced compared to that of the PD system; in fact with no superimposed dead load, the measured stiffness with a full deck was slightly larger than that with a partial deck, which agrees with the intuitive expectation that adding more PMDF panels would increase the system stiffness. As was noted earlier in this paper and reported in Egilmez et al. (2006), the PMDF loaded with concrete panels better represents the stiffness of the PMDF systems in practice. As noted, there was very little difference between the PD and FD tests, only FD systems were evaluated in later tests.

For all sheet metal thicknesses, the addition of stiffening angles increased the lateral stiffness of the system compared to the companion unstiffened PMDF test. For example, in Table 2 the lateral stiffness for the FD-Case A loading went from $2,374 \mathrm{kN} / \mathrm{m}$ for the unstiffened deck to $3,676 \mathrm{kN} / \mathrm{m}$ for the system with stiffening angles spaced at $2.4 \mathrm{~m}$. The $2.4 \mathrm{~m}$ stiffening angle spacing provided the largest lateral stiffness for the Case A and Case $\mathrm{C}$ loadings in all but one test. The stiffness values for the 4.9 and $7.3 \mathrm{~m}$ stiffening angle spacings were slightly smaller but comparable to that of the $2.4 \mathrm{~m}$ stiffening angle spacing. The one exception where the $2.4 \mathrm{~m}$ spacing resulted in a slightly lower stiffness than the larger spacings was for the $0.91 \mathrm{~mm}$ thick FD system with the Case $C$ loading. The reason for this smaller stiffness in this isolated case was not evident and was considered an aberration.

Table 3. Modified W760 $\times 134$ with $\mathrm{L} 76 \times 51 \times 3.3$ Angles and $1.22 \mathrm{~mm}$ Thick PMDF

\begin{tabular}{|c|c|c|c|c|c|c|c|c|}
\hline \multirow[b]{2}{*}{ Basis } & \multirow[b]{2}{*}{ PMDF type } & \multirow{2}{*}{$\begin{array}{c}\mathrm{G}^{\prime} \\
(\mathrm{kN} / \mathrm{m}- \\
\mathrm{rad})\end{array}$} & \multirow[b]{2}{*}{$\begin{array}{c}\text { PD-Case A } \\
(\mathrm{kN} / \mathrm{m})\end{array}$} & \multirow[b]{2}{*}{$\begin{array}{c}\text { FD-Case A } \\
(\mathrm{kN} / \mathrm{m})\end{array}$} & \multirow[b]{2}{*}{$\begin{array}{c}\text { FD-Case B } \\
(\mathrm{kN} / \mathrm{m})\end{array}$} & \multicolumn{3}{|c|}{ FD-Case C } \\
\hline & & & & & & $\begin{array}{c}\text { Midspan } \\
(\mathrm{kN} / \mathrm{m})\end{array}$ & $\begin{array}{c}\text { Qtr-point } \\
(\mathrm{kN} / \mathrm{m})\end{array}$ & $\begin{array}{c}\text { Total } \\
(\mathrm{kN} / \mathrm{m})\end{array}$ \\
\hline \multirow[t]{4}{*}{$\mathrm{Lab}$} & Unstiffened & - & $3,292^{\mathrm{a}}$ & 3,004 & 1,997 & 1,442 & 1,116 & 2,558 \\
\hline & Stiffened @2.4 m & - & $6,094^{\mathrm{a}}$ & 5,950 & 3,387 & 2,067 & 3,222 & 5,284 \\
\hline & Stiffened@4.9m & - & - & $5,758^{\mathrm{a}}$ & 2,625 & 1,767 & 3,134 & 4,901 \\
\hline & Stiffened@7.3 m & - & - & $5,652^{\mathrm{a}}$ & 3,042 & 2,069 & 2,859 & 4,928 \\
\hline \multirow[t]{4}{*}{ FEA } & Unstiffened & 2,575 & 3,292 & 3,292 & 1,734 & 981 & 1,786 & 2,767 \\
\hline & Stiffened @2.4 m & 4,905 & 6,094 & 6,130 & 3,187 & 1,874 & 3,292 & 5,166 \\
\hline & Stiffened @4.9 m & 4,029 & - & 5,758 & 3,006 & 1,762 & 3,102 & 4,864 \\
\hline & Stiffened@7.3 m & 4,765 & - & 5,652 & 2,924 & 1,716 & 3,048 & 4,764 \\
\hline
\end{tabular}

${ }^{\mathrm{a}}$ Denotes laboratory test used to calibrate FEA model. 


\begin{tabular}{|c|c|c|c|c|c|c|c|c|}
\hline \multirow[b]{2}{*}{ Basis } & \multirow[b]{2}{*}{ PMDF type } & \multirow[b]{2}{*}{$\begin{array}{c}\mathrm{G}^{\prime} \\
(\mathrm{kN} / \mathrm{m}-\mathrm{rad})\end{array}$} & \multirow{2}{*}{$\begin{array}{c}\text { Deck } \\
\text { thickness } \\
(\mathrm{mm})\end{array}$} & \multirow[b]{2}{*}{$\begin{array}{c}\text { FD-Case A } \\
(\mathrm{kN} / \mathrm{m})\end{array}$} & \multirow[b]{2}{*}{$\begin{array}{c}\text { FD-Case B } \\
(\mathrm{kN} / \mathrm{m})\end{array}$} & \multicolumn{3}{|c|}{ FD-Case C } \\
\hline & & & & & & $\begin{array}{c}\text { Midspan } \\
(\mathrm{kN} / \mathrm{m})\end{array}$ & $\begin{array}{c}\text { Qtr-point } \\
(\mathrm{kN} / \mathrm{m})\end{array}$ & $\begin{array}{c}\text { Total } \\
(\mathrm{kN} / \mathrm{m})\end{array}$ \\
\hline $\mathrm{Lab}$ & Stiffened@4.9m & - & 0.91 & $5,324^{\mathrm{a}}$ & 2,586 & 1,438 & 3,215 & 4,653 \\
\hline FEA & Stiffened@4.9m & 4,204 & & 5,324 & 2,749 & 1,629 & 2,872 & 4,501 \\
\hline \multirow[t]{2}{*}{ Lab } & Unstiffened & - & 1.22 & $4,028^{\mathrm{a}}$ & 2.542 & 1,820 & 1,718 & 3,538 \\
\hline & Stiffened@4.9m & - & & $6,510^{\mathrm{a}}$ & 3,399 & 1,832 & 4,355 & 6,187 \\
\hline \multirow[t]{2}{*}{ FEA } & Unstiffened & 3,118 & & 4,028 & 2,136 & 1,226 & 2,172 & 3,398 \\
\hline & Stiffened@4.9m & 5,413 & & 6,510 & 3,397 & 1,996 & 3,538 & 5,534 \\
\hline
\end{tabular}

${ }^{\mathrm{a}}$ Denotes laboratory test used to calibrate FEA model.

Another trend in Table 2 that may not appear to fit intuition is the pattern of results for the FD-Case B tests. In the FD Case B tests, the stiffness of the system with the $7.3 \mathrm{~m}$ stiffening angle spacing was larger than that of the system with more closely spaced stiffening angles positioned at $4.9 \mathrm{~m}$ intervals. The reason the stiffness was smaller for the tighter $4.9 \mathrm{~m}$ stiffening angle spacing is that with the $4.9 \mathrm{~m}$ spacing, there is not a stiffening angle at midspan. With both the 2.4 and $7.3 \mathrm{~m}$ stiffening angle spacings there is a stiffening angle at midspan as shown in Fig. 5, and as in Case B the load is actually applied at midspan, the absence of a stiffening angle at midspan with the $4.9 \mathrm{~m}$ spacing results in a softer system.

When comparing the FEA results with the experimental values in Tables 2 and 3, as would be expected the FEA results agree exactly with the corresponding lab values denoted with an asterisk as the lab values marked with an asterisk were the tests used to calibrate, or size, the finite-element shear diaphragms. For the other cases, the FEA models either slightly underestimated or overestimated the lab results. As was explained above, the FEA model slightly overestimated the stiffness of the FD systems with the Case A loading as the FEA model did not consider the $P$-delta effect that occurred from the superimposed concrete load. For the Case B (midspan) loading with the FD system, the FEA model tended to underestimate the lateral stiffness of the PMDF braced system. In reality, the PMDF system has both shear stiffness and in-plane flexural stiffness. As in the FEA model the PMDF was modeled as a shear diaphragm, which possesses only shear stiffness and no in-plane flexural stiffness, it is not unsurprising that the FEA results underestimate the stiffness values for Case B. In Case B the load is applied at midspan, where the PMDF sheets are subjected to the most significant in-plane flexural deformations.

The in-plane flexural stiffness also affected the distribution of the stiffness values that are reported for the Case $\mathrm{C}$ loading. The measured stiffness values at the quarter points and midspan differ significantly from those predicted by the FEA model. However, although the individual midspan and quarter-point FEA stiffness values differ substantially from the lab results, there is better agreement between the FEA and lab results for the total stiffness values which are reported in the last column of the table. Overall the FEA model sized using the lateral stiffness values obtained from Case A did a good job of predicting the behavior for the Case $\mathrm{B}$ and Case $\mathrm{C}$ loadings and also the response of the system during buckling tests. Comparisons of the FEA results with the girder buckling tests will be presented in a future paper.

Evaluation of the laboratory measurements for the $0.91 \mathrm{~mm}$ thick forms in Table 2 and the $1.22 \mathrm{~mm}$ thick forms in Table 3 show a significant increase in the lateral stiffness with the thicker forms. For example, for the FD system stiffened at $2.4 \mathrm{~m}$ with the
Case A loading, the stiffness increased from $3,676 \mathrm{kN} / \mathrm{m}$ for the $0.91 \mathrm{~mm}$ thick deck in Table 2, to $5,950 \mathrm{kN} / \mathrm{m}$ for the $1.22 \mathrm{~mm}$ thick deck in Table 3. Similar increases were observed in comparisons of other lab test data for the $0.91 \mathrm{~mm}$ versus the $1.22 \mathrm{~mm}$ thick deck. Although an increase in stiffness would be expected with thicker forms, this trend did not hold true when comparing the $1.22 \mathrm{~mm}$ results to corresponding values for the $1.63 \mathrm{~mm}$ thick deck. Note that the results for the $1.63 \mathrm{~mm}$ deck are not presented here but were reported by Egilmez (2005). The reason the stiffness values were lower with the thicker $1.63 \mathrm{~mm}$ forms compared to the $1.22 \mathrm{~mm}$ forms was because there were smaller fastener edge distances in the tests of the $1.63 \mathrm{~mm}$ deck. In cases where the forms are slightly shorter than specified or where imperfections in adjacent girders differ, the edge distance for the fasteners may be reduced. The small fastener edge distances that were observed with the $1.63 \mathrm{~mm}$ deck explain the reduced stiffness values measured for these forms. The possibility of small fastener edge distances, and the subsequent reduction in bearing capacity, was the main reason the conventional L76 $\times 51 \times 3.3$ angles were replaced with $L 76 \times 76 \times 3.3$ angles in later tests.

\section{Decked Twin-Girder System with L76 $\times 76 \times 3.3 \mathrm{~mm}$ Support and Stiffening Angles}

Using a longer leg where the PMDF is attached to the support and stiffening angles resulted in fastener edge distances that were much more reliable. These larger edge distances improved both the stiffness and strength characteristics of the forms. The stiffness values for the tests reported in Table 4, with the larger L76 $\times 76 \times 3.3$ support and stiffening angles, were substantially greater than the corresponding results for the $\mathrm{L} 76 \times 51 \times 3.3$ angles presented in Tables 2 and 3. Note that the fourth column in Table 3 indicates the deck thickness used in each test. Based upon the improved performance with the larger angle, use of L76 $\times 76 \times 3.3 \mathrm{~mm}$ support and stiffening angles is recommended. This angle size will be used in the TxDOT bridges that will implement use of PMDF as girder bracing.

\section{Summary}

Metal forms are generally not relied upon for stability bracing in the bridge industry because of the flexibility in the deck form connection detail that is currently used in these bridges. A modification to the connection detail was developed as part of the research study documented in this paper. The modified detail has resulted in a significant increase in the stiffness of the PMDF systems, and this improved stiffness enhances the bracing potential of the deck forms used in bridges. The overall research study 
of PMDF as bracing was divided into three phases: shear panel tests, lateral displacement tests, and buckling tests. This paper has focused on the shear panel and lateral displacement tests. The results from the lateral displacement tests have provided valuable data that has been used in calibration of FEA models of deck forms modeled as shear diaphragms. The FEA models developed using the lateral displacement test results can now be used to predict the buckling response of girder systems braced with deck forms. The results provided in this paper can serve as a reference for bridge deck stiffness values, and also as a basis of calibration for other researchers investigating the bracing potential of bridge deck forms.

\section{References}

American Association of State Highway and Transportation Officials (AASHTO). (2002). Standard specifications for highway bridges, 17th Ed., Washington, D.C.
ANSYS Inc. (2004). Finite element program users' manual, Version 8.0, Canonsburg, Pa.

Egilmez, O. O. (2005). "Lateral bracing of steel bridge girders by permanent metal deck forms," Ph.D. dissertation, Univ. of Houston, Houston.

Egilmez, O. O., Helwig, T. A., and Reagan, H. (2006). "Stiffness requirements for metal deck forms used for stability bracing of steel bridge girders." Proc., 2006 Structural Stability Research Council Annual Conf., 203-222.

Helwig, T., Egilmez, O., and Jetann, C. (2005). "Lateral bracing of bridge girders by permanent metal deck forms," Research Rep. No. 0-4145-1, Texas Department of Transportation.

Helwig, T. A., and Yura, J. A. (2006). "Shear diaphragm bracing of beams. I: Stiffness and strength behavior." J. Struct. Eng., 134(3), 348-356.

Texas Department of Transportation (TxDOT). (2004). Permanent metal deck form standards, TxDOT Bridge Division. 